\title{
Association of Climate-related Total Atmospheric Energy Anomalies in the Tibetan Plateau with Haze in eastern China
}

\author{
Xiaodan $\mathrm{Ma}^{1}$, Xiangde $\mathrm{Xu}^{2}$, Xinghong Cheng ${ }^{2 *}$, Tianliang $\mathrm{Zhao}^{{ }^{*}}$, Lili Dong ${ }^{3}$, Yang Zhao ${ }^{2,4}$, \\ Xiaoyun Sun ${ }^{1}$
}

${ }^{1}$ Collaborative Innovation Center on Forecast and Evaluation of Meteorological Disasters, Key Laboratory for AerosolCloud-Precipitation of China Meteorological Administration, Nanjing University of Information Science and Technology, Nanjing 210044, China

${ }^{2}$ Chinese Academy of Meteorological Sciences, Beijing 100081, China

${ }^{3}$ National Climate Center, Beijing 100081, China

${ }^{4}$ Department of Atmospheric and Oceanic Sciences, McGill University, Montreal, Quebec, Canada

\begin{abstract}
As climate warming is widespread over the world, the Tibetan Plateau is particularly sensitive to climate warming impacts owing to its high elevations and complex topography, receiving worldwide attention for its significant feedbacks through affecting the atmosphere circulation, and thus the Asia climate system even to global. In this study, the new metric "total atmospheric energy", is considered to investigate the association of thermal anomalies on the Tibetan Plateau with haze events in China. The total atmospheric energy (TPE) of the Tibetan Plateau, including sensible heat energy, potential energy, kinetic energy, and latent heat energy, was calculated using US National Center for Environmental Prediction (NCEP) meteorological reanalysis data from 1980 to 2016 to characterize the atmospheric thermal forcing of the large topography of the Tibetan Plateau. Results show that TPE has displayed periods of increase levels in recent decades, and inter-annual variations of TPE are significantly positively correlated with winter haze days over northern China but are negatively associated with haze events in southern China. Further diagnostic analysis and simulated results using the Weather Research and Forecasting (WRF)-Chem model indicate that the anomalous increase of TPE leads to enhanced thermal stability of the lower atmosphere, a weakened East Asian winter monsoonal wind in northern China, and increased near-surface wind speed in southern China, which are conductive to positive $\mathrm{PM}_{2.5}$ anomalies in northern China and negative $\mathrm{PM}_{2.5}$ anomalies in southern China. This implies that meteorological changes induced by TPE anomalies may play an important role in wintertime haze pollution over different regions of eastern China. Understanding the climate-related TPE modulating the favourable meteorological conditions for winter haze pollution over Eastern China could contribute to long-term planning for air pollution control.
\end{abstract}

Keywords: Tibetan Plateau; Total atmospheric energy; Haze; Thermal forcing.

\section{INTRODUCTION}

Increased air pollution in China has commonly been attributed to large increases in pollutant emissions associated with China's rapid economic development (Fu and Chen, 2017). To cope with the air pollution problem, the Chinese government has made considerable efforts to reduce emissions of atmospheric pollutants nationwide in recent years. However, regions in China still experience haze pollution, which results from the synergetic interactions between anthropogenic

\footnotetext{
* Corresponding author.

E-mail address: cxingh@cma.gov.cn (X. Cheng); tlzhao@nuist.edu.cn (T. Zhao)
}

emissions and atmospheric processes (An et al., 2019). Thus, the reduction of haze days should not be entirely attributed to improved air-quality control measures without accounting for the effects of climate variability. For example, the rapid warming of the Barents-Kara Sea region in association with El Niño/Southern Oscillation (ENSO) and Arctic warming enhances the Siberian High, and thus played an important role in the improvement of air quality during winter 20172018 in the North China Plain (Yi et al., 2019).

The processes of particulate matter accumulation and secondary formation could be enhanced under stagnant meteorological conditions, characterized by high relative humidity (RH), low planetary boundary layer height, and weak near-surface winds (Ma et al., 2017a; Zhong et al., 2017; Huang et al., 2018; Jiang et al., 2019; Sun et al., 2019). Certain weather conditions triggered by climate change can 
promote severe winter haze, including reduced surface winter northerlies (Renhe et al., 2014; Chen and Wang, 2015), weakened north-westerlies in the mid-troposphere, and enhanced thermal stability of the lower atmosphere (Feng et al., 2010; Renhe et al., 2014; Chen and Wang, 2015; Li et al., 2015; Cai et al., 2017). Winter East Asian monsoons (EAMs), as the major components of the climate system of the Northern Hemisphere, are characterized by strong northerly winds from the cold-core Siberia-Mongolia High (Ding, 1994). Climate change could modulate the interannual variations in aerosols and air quality over centraleastern China by changing near-surface winds, precipitation, and atmospheric boundary layer associated with EAMs (Cheng et al., 2016).

Previous studies have linked poor air quality and extreme haze in China with weakened circulation in the East Asian winter monsoon (Feng et al., 2010), Arctic sea ice loss (Zou et al., 2017), the positive phase of the Pacific Decadal Oscillation (Zhao et al., 2016), ENSO (Hui and Xiang, 2015; Feng et al., 2016), and variability in Pacific Ocean surface temperature (Yin and Wang, 2016; Lin et al., 2018). However, climate effects from the Tibetan Plateau (TP) have not been considered widely. As the "Third Pole" of the Earth, the TP has significant dynamic and thermal effects on East Asian climate patterns, the Asian monsoon process, and atmospheric circulation in the Northern Hemisphere (Wu et al., 2007; Ma et al., 2017b). Climate change and the constant deposition of light-absorbing particles on TP snow have affected the environment of the TP, and many studies in recent decades have reported striking climate warming has been reported by throughout the TP (Liu et al., 2000; Duan et al., 2006; Ji, 2018).

Much research has focused on the effects of TP mechanical or thermodynamic forcing on the broader region beyond climate (Ye, 1979; Yanai and $\mathrm{Wu}, 2006$ ). However, the mechanisms linking the TP climate change with severe winter haze in eastern China have not been thoroughly investigated. $\mathrm{Xu}$ et al. (2016) conducted a composite analysis of weather conditions, indicating that frequent haze occurrences in centraleastern China are consistent with increasing atmospheric stability in the lower troposphere, decreasing winter monsoon winds, and intensifying downward air flows in association with the upstream plateau's thermal anomalies. In this study, we attempt to continue Xu's formal research and use a new metric - atmospheric energy - to investigate the association of TP thermal anomalies with haze frequency in eastern China. Efforts of understanding the significant correlation and the physical relationships linking climate-related TPE with wintertime haze pollution over eastern China, is good for studying wintertime haze pollution over eastern China extensively using a combination of climate indices in the future.

This paper is organized as follows: In the Methods, we will first define and describe a method to calculate the total atmospheric energy of the TP. The results of an analysis of the associations between haze and total atmospheric energy over the TP region and related mechanisms along with model confirmations are given in the Results and Discussion. The Conclusions provides some final remarks and a summary.

\section{METHODS}

\section{Data and Methodology}

In this study, we used the sounding observational records of isobaric surface potential height, air temperature, dew point temperature, wind direction, and wind speed from 2000 to 2016 archived at the China Meteorological Administration (CMA) and the meteorological variables of air temperature, wind speed, and relative humidity from the reanalysis data generated by the US National Center for Environmental Prediction-National Center for Atmospheric Research (NCEP/NCAR). Haze pollution in China occurs in all seasons but is most frequent and severe in winter (Ding and Liu, 2014; Fu et al., 2014). Thus, we focus on winter to study the thermal and mechanical forcing of the TP on haze pollution. Accordingly, ground-based observations of the frequency of winter haze events from 1980 to 2016 archived at CMA were also adopted in this study. According to a wavelet analysis of pollutants, the contribution of emissions displays a low frequency pattern (Gong et al., 2010). To separate the influence of emissions and meteorology, we assume that emissions have been increasingly contributing to haze at a constant rate, so the variation in haze pollution mainly attributable to meteorological effects can be estimated by removing the linear trend in haze days.

In previous studies, TP thermal forcing was represented as an apparent heat source (Q1) to investigate the processes linking TP climate change with haze pollution over centraleastern China (Xu et al. 2016). Here, however, we propose using total atmospheric energy to reveal the effect of climate change-related thermal forcing of the TP on haze pollution in eastern China. To identify the main influencing pathways between TP atmospheric energy and meteorological conditions in haze-prone areas, we performed correlation analyses between total atmospheric energy over the TP (TPE) and meteorological variables (the $\mathrm{U}, \mathrm{V}$, and $\mathrm{W}$ components of wind and temperature).

The nationwide observational network designed to monitor urban and suburban air pollution in mainland China became operational in 2013. Thus, simulation experiments with TPE values calculated using data collected from 2013-2017 were conducted for further validation via modelling. We adopted the state-of-the-art Weather Research and Forecasting (WRF)Chem model (version 3.7) to simulate two cases in December with high TPE $\left(97.98 \times 10^{6} \mathrm{~J} \mathrm{~m}^{-2}\right)$ in 2016 and low TPE $\left(95.85 \times 10^{6} \mathrm{~J} \mathrm{~m}^{-2}\right)$ in 2013 using the same anthropogenic aerosol emissions recorded in the MIX Asian anthropogenic emission inventory in 2010 ( $\mathrm{Li}$ et al., 2017) to ensure a consistent influence from anthropogenic emissions. The differences in aerosol concentrations and meteorological variables in a high TPE year and low TPE year are considered to reflect the impact of the TP's climate modulation on air pollution in eastern China. The WRF-Chem simulation experiments were configured with 41 vertical levels up to $10 \mathrm{hPa}$, as well as $30 \times 30 \mathrm{~km}$ horizontal model grids across the whole China.

\section{TPE Calculation}

Following the definition presented by Sheng (2013), the 
total atmospheric energy of wet air in per unit mass $\left(E_{m}\right)$ was calculated using Eq. (1). As total atmospheric energy includes sensible heat energy, potential energy, kinetic energy, and latent heat energy, TP climate change can be well described through the vertical integration of total atmospheric energy in the troposphere averaged over the TP area. Thus, we obtained the TPE (per $\mathrm{J} \mathrm{m}^{-2}$ ) by integrating total atmospheric energy from the surface to $300 \mathrm{hPa}$ (the height of the tropopause) and averaging it over the TP area of $80-105^{\circ} \mathrm{E}$ and $27.5-37.5^{\circ} \mathrm{N}$.

$$
E_{m}=c_{p} T+g z+\frac{1}{2} V^{2}+L q
$$

where $T, z, V, q$ represent temperature, altitude, wind speed, and specific humidity, respectively. Specific heat at constant pressure $\left(c_{p}\right)$, acceleration of gravity $(g)$, and latent heat of phase change $(L)$ are constants set at $1004.07 \mathrm{~J} \mathrm{~kg}^{-1} \mathrm{~K}^{-1}$, $9.8 \mathrm{~m} \mathrm{~s}^{-2}$, and $2501000 \mathrm{~J} \mathrm{~kg}^{-1}$, respectively.

\section{Validation of Calculated TPE over the TP}

To validate the accuracy of TPE calculated using NCEP reanalysis data, we employed sounding observational data to recalculate TPE. The NCEP reanalysis data were interpolated onto the sounding observational sites over the TP region for validation of calculation. The results shown in Fig. 1 demonstrate the consistency between the TPE derived from NCEP reanalysis data and observed meteorological data, with a significant correlation coefficient $r=0.43$. Therefore, the total atmospheric energy calculated using NCEP reanalysis data is suitable for use in the long-term climatological analysis that follows.

\section{RESULTS AND DISCUSSION}

\section{Associations between Inter-annual Changes of TPE and Haze}

China has experienced a significant increase in haze occurrences in recent decades (An et al., 2019). We separated 37 years' haze data into two phrases, the first 20 years of 1980-1999 and the latter 17 years of 2000-2016 according to variations in haze-occurrence change-rate trends in China (Xu et al., 2016). As shown in Figs. 2(a) and 2(b), hazeoccurrence change rates displayed heterogeneous trends with both positive and negative changes in the first stage, while sharply rising by more than $3 \mathrm{~d}_{10} \mathrm{a}^{-1}$ going into the twenty-first century at the most of observation sites across China. The synergetic effects from multi-factors have been identified to regulate the higher frequency and severity of haze formation, including high emissions of primary particles and gaseous PM precursors from multiple sources, efficient secondary PM formation, regional transport, adverse meteorological and climatic conditions (An et al., 2019). Accordingly, TPE changes were also analysed in two stages in Figs. 2(c) and 2(d), exhibiting small decreasing trends in the southern TP in the first phrase and clear increasing trends throughout the TP in the second phase. Observations have revealed the impacts of climate warming on the TP area, such as the degradation of frozen grounds, glacial recession, a trend in decreasing snow coverage, the expansionist number of glacial lakes, even positive feedback and accelerated warming from atmospheric carbon (Liu et al., 2000; Duan et al., 2006; Yang et al., 2010; Zhenming, 2018; Fang et al., 2019). The continual increase in Chinese pollutant emissions is undoubtably the main contributor to inter-annual variations in winter haze occurrences, but the significant increase of

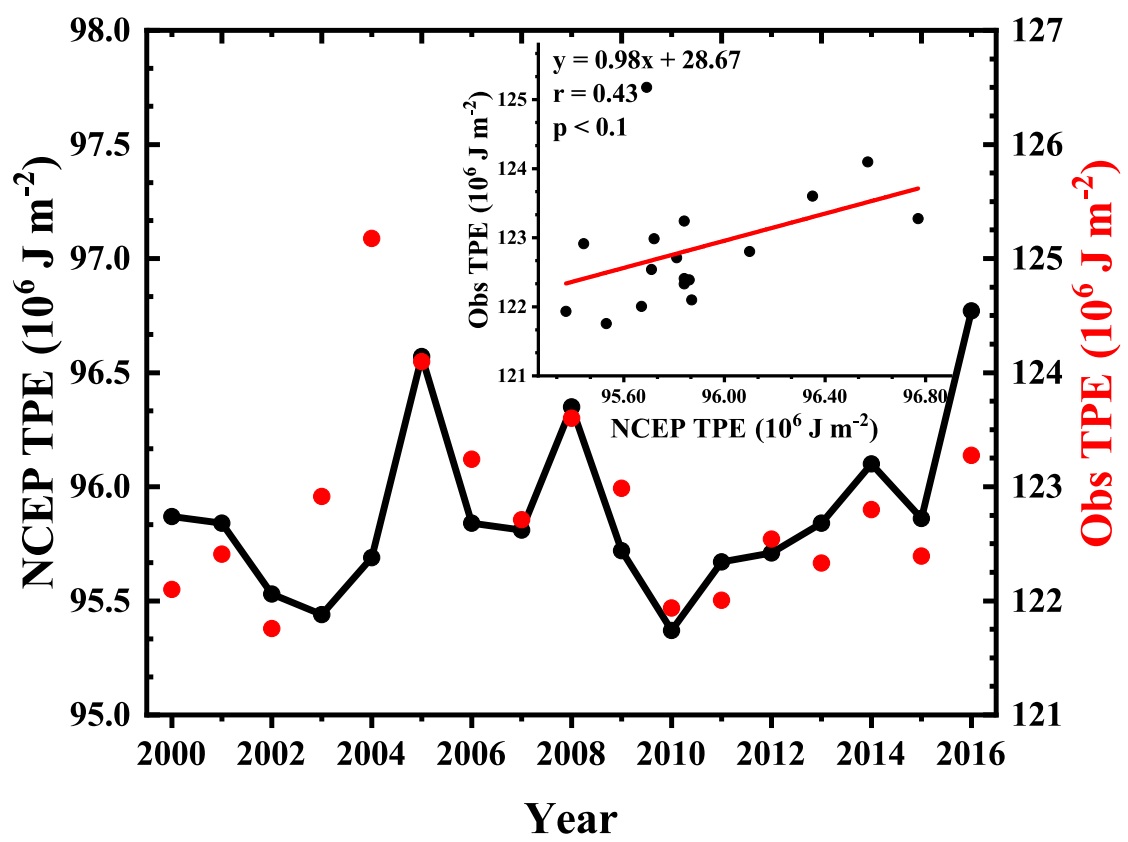

Fig. 1. Validation of TPE calculated using NCEP reanalysis data (solid black line) with observational data (red dots) over 2000-2016. Their relationship is shown in the embedded figure. (TPE: Tibetan Plateau's total atmospheric energy; NCEP: National Center for Environmental Prediction; Obs: observed) 

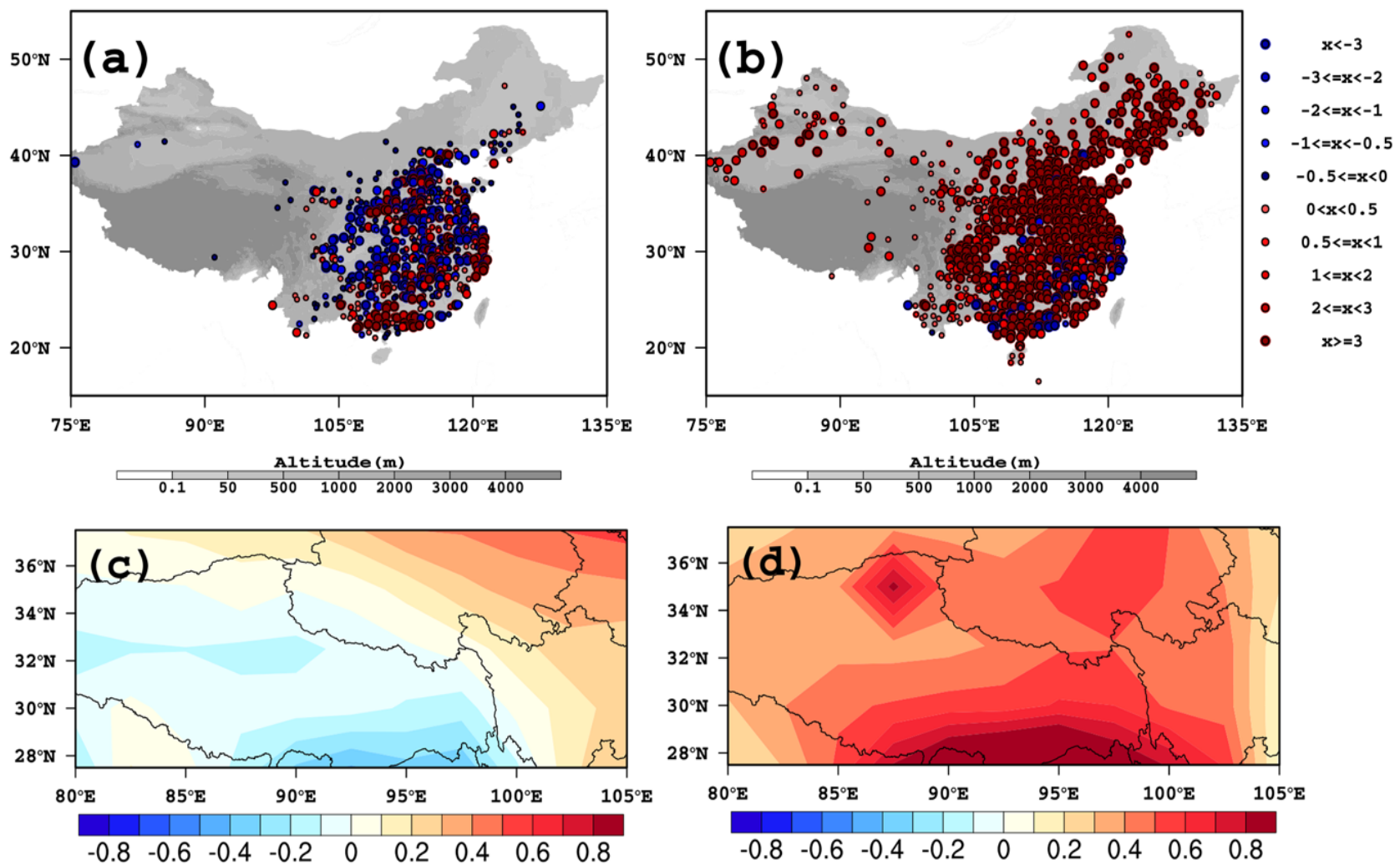

Fig. 2. Change rates in winter haze occurrences ( $\left.10 \mathrm{a}^{-1}\right)$ during (a) 1980-1999 and (b) 2000-2016, and change rates of winter total atmospheric energy $\left(10^{6} \mathrm{~J} \mathrm{~kg}^{-1} 10 \mathrm{a}^{-1}\right)$ over the Tibetan Plateau during (c) 1980-1999 and (d) 2000-2016.

TPE may also play an important role in the variations of haze events in China.

Under high pollutant emissions, the impact of climate modulation on haze events can be amplified (Gao et al., 2019). Since haze pollution was relatively severe during the second phase (2000-2016), our correlation analysis of TPE and haze occurrences focuses on the second phase rather than the entire study period. Haze occurrences were de-trended by removing liner trends in each sample to mitigate the influence of low-frequency emissions and reveal the impact of meteorological conditions. The correlation coefficients of TPE and de-trended haze days indicate differences between northern and southern China (Fig. 3). Coloured dots with a black outline indicate correlations that surpass the $95 \%$ significance level. TPE is positively correlated with haze occurrences in northern China while negatively associated with haze events in southern China. Possible reasons for this pattern of TPE-modulation effects on haze events are discussed below.

\section{Meteorological Mechanisms Induced by TPE Anomalies}

Conducive weather conditions are an important factor in severe haze episodes. To identify the association between TPE and a thermal stable atmosphere over eastern China, the inter-annual correlations between TPE and air temperature were analysed (Fig. 4). The vertical temperature profile features warm anomalies in the lower troposphere and anomalous cooling in the upper atmosphere in response to TPE increases. Horizontally, the region of warm anomalies stimulated by anomalously increased TPE covers all of eastern China, resulting in a more stably stratified atmosphere. The vast range of anomalous warmth in the lower troposphere can prevent the vertical dispersion of pollutants (Renhe et al., 2014; Chen and Wang, 2015). High emissions of primary particles and gaseous particulate matter (PM) precursors from multiple sources have commonly been identified as one of the main factors regulating the frequency and severity of haze formation (Guo et al., 2014; Huang et al., 2014; Shang et al., 2018; Yu et al., 2018; Liu et al., 2019). Since developed regions with rapid industrialization and urbanization and high pollutant emissions are mainly centred in northern China, including Beijing-Tianjin-Hebei and the Yangtze River Delta (An et al., 2019), the thermal stable atmosphere induced by TPE anomalies may have more amplified effects in northern China than in southern China.

In Fig. 5(a), two correlation coefficients of TPE to U and $\mathrm{V}$ wind components at $850 \mathrm{hPa}$ are defined as two horizontal components of correlation vectors, respectively, where the arrow length denotes the combined correlation. A longer arrow implies a stronger correlation, and the arrow direction shows the direction of anomalous wind induced by TPE thermal forcing. Compared with the averaged stream measured at $850 \mathrm{hPa}$ in winter during 1980-2016 over China (Fig. 5(b)), TPE thermal forcing weakens the winter monsoon winds by inducing anomalous southeast wind in northern China and anomalous southwest wind along the second terrain ladder in southern China. In northern China, reduced seasonal prevailing cold surface northerlies are conducive to the warm, stable 


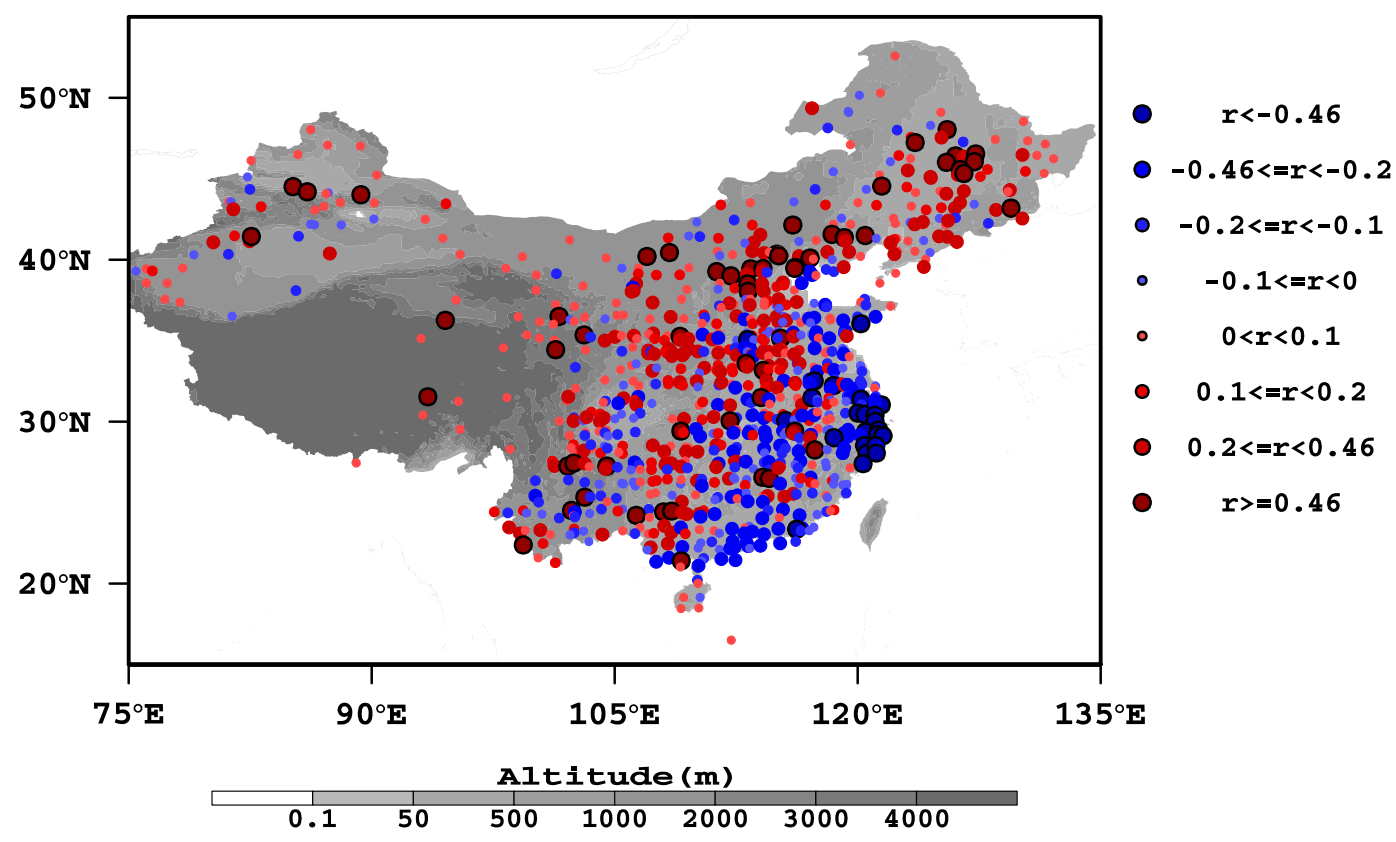

Fig. 3. Distribution of correlations between TPE and de-trended haze days during 2000-2016. Coloured dots with black outlines indicate a 95\% significance level.
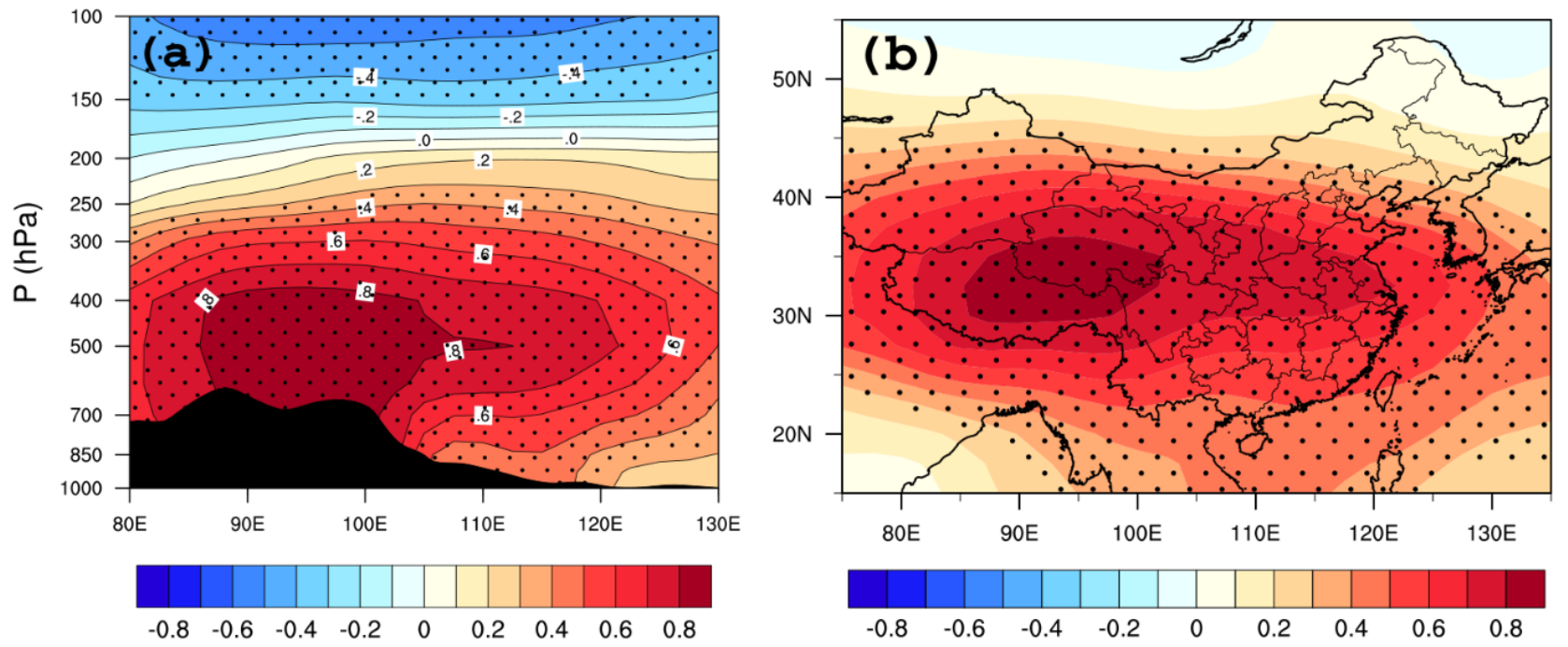

Fig. 4. Distributions of inter-annual correlations between TPE and (a) vertical air temperature averaged along $27-41^{\circ} \mathrm{N}$ and (b) air temperature at $500 \mathrm{hPa}$ in winter during 1980-2016. Dots denote areas with a 95\% significance level.

atmospheric conditions, which are favourable for haze formation and maintenance. However, in southern China, southerlies with clean air strengthen the relatively weak near-surface wind speed and promote the dispersion of air pollution.

In summary, increased TPE can cause more rapid warming in the lower troposphere and reduced surface winter northerlies over northern China, which are unfavourable for the horizontal and vertical dispersion of pollutants. In southern China, simulated anomalous southerlies actually enhance the wind speed across an area with low winter wind speeds. Therefore, the TP's thermal forcing leads to anomalous changes in the thermal stability of the lower atmosphere and winter prevailing northerlies, which, in addition to higher pollutant emissions in northern China than in southern China, have different impacts on haze pollution over these regions. These results were suggested by the correlation analysis between TPE and haze events presented previously. To further confirm the mechanism analysis of the effects of the TP's climate modulation, we conducted two experiments using the WRF-Chem model with different TPE scenarios.

\section{Simulation Experiments \\ Model Validation}

The $\mathrm{PM}_{2.5}$-concentration simulation results were compared with observed data, as presented in Fig. 6. Figs. 6(a) and 6(b) 

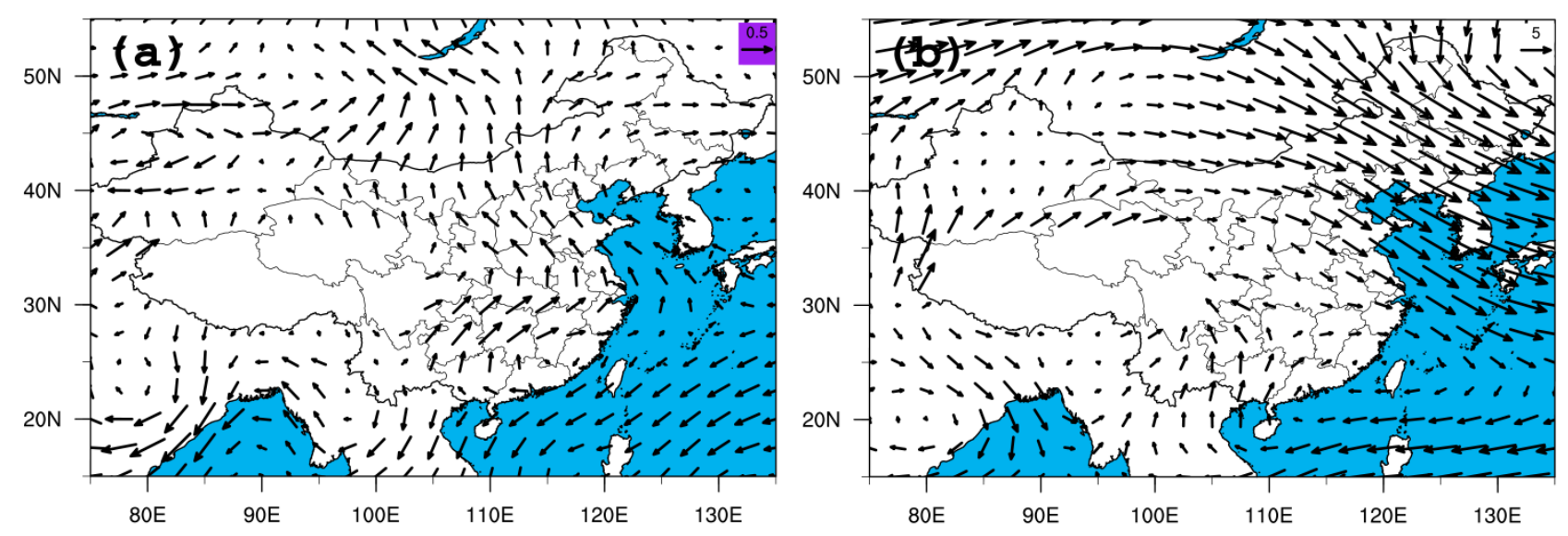

Fig. 5. Distribution of (a) inter-annual correlations of TPE to both U and V wind components and (b) averaged stream reported at $850 \mathrm{hPa}$ in winter over 1980-2016.
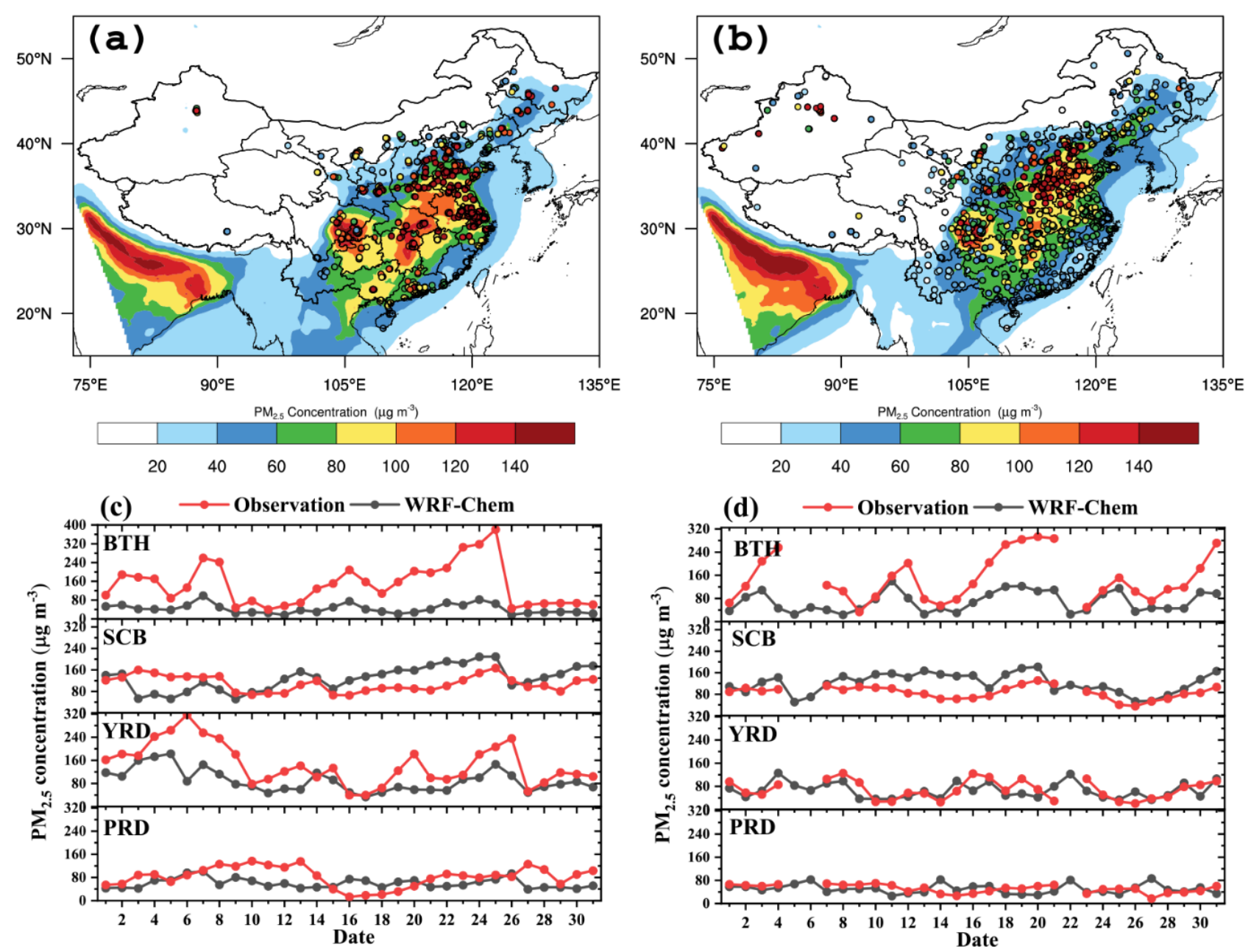

Fig. 6. Spatial distributions of simulated (contoured) and observed (circled) monthly averaged $\mathrm{PM}_{2.5}$ concentrations $\left(\mu \mathrm{g} \mathrm{m}^{-3}\right.$ ) in (a) December 2013 and (b) December 2016. Daily variations of observed (red lines) and simulated (black lines) PM P..5 $_{2}$ the Beijing-Tianjin-Hebei (BTH), Yangzi River Delta (YRD), Sichuan Basin (SCB), and Pearl River Delta (PRD) regions in (c) December 2013 and (d) December 2016.

show the spatial distribution of average monthly $\mathrm{PM}_{2.5}$ concentrations in December of 2013 and 2016, respectively. Daily variations of $\mathrm{PM}_{2.5}$ concentrations were estimated for four regions: Beijing-Tianjin-Hebei (BTH), the Yangzi River Delta (YRD), the Sichuan Basin (SCB), and the Pearl River Delta (PRD). The model results were interpolated 
onto observation sites in each region, and then the regional averaged model results are compared with the observed $\mathrm{PM}_{2.5}$ concentrations in December of 2013 and 2016 (Figs. 6(c) and $6(\mathrm{~d})$, respectively). According to the spatial and temporal distributions of $\mathrm{PM}_{2.5}, \mathrm{PM}_{2.5}$ concentrations were sometimes underestimated due to the relatively lower anthropogenic aerosol emissions used in model. The day with 24-hr average $\mathrm{PM}_{2.5}$ concentration exceeding $75 \mu \mathrm{g} \mathrm{m}^{-3}$ is identified as a haze event (Grade II National Ambient Air Quality Standard). $\mathrm{PM}_{2.5}$ exceedance frequency of model results indicating that the haze episodes were captured quite well, confirming that the contribution of meteorological conditions influenced by anomalous TPE changes to haze pollution were reasonably well reproduced.

\section{Anomalies Attributable to High TPE}

The differences between a high-TPE year and low-TPE year were analysed to determine the influence of increased TPE. As shown in Fig. 7, approximately $20 \mu \mathrm{g} \mathrm{m}^{-3}$ positive $\mathrm{PM}_{2.5}$ anomalies in northern China and negative $\mathrm{PM}_{2.5}$ anomalies in southern China correspond to a TPE increase of approximately $2.13 \times 10^{6} \mathrm{~J} \mathrm{~m}^{-2}$. The aerosol anomaly pattern indicated by the model results is consistent with results of the correlation analysis between TPE and haze occurrences presented previously. Compared to the low-TPE year shown in Fig. 8(a), the simulation of the high-TPE year revealed a warmer low tropospheric atmosphere with $1-5^{\circ} \mathrm{C}$ temperature increases, which are unfavourable for the vertical dispersion of pollutants. Further, a weakened East Asian winter monsoon was observed in Fig. 8(b) with a $4 \mathrm{~m} \mathrm{~s}^{-1}$ wind speed decrease in eastern China. In high TPE year, weakened northerlies provided warm and stable atmospheric conditions in northern China. While strengthened southerlies with clean air in southern China contributed to pollution dispersion. Emissions distribution from the MIX inventory shows that primary $\mathrm{PM}$ emission rates are larger in northern China than in southern China (Fig. 9). High emission rates and unfavourable ventilation conditions in northern China together are conductive to frequent haze events, while anomalous strengthened southerlies as well as low emission rates in southern China may contribute to less air pollution. Therefore, it should be noted that northern China with higher pollutant emissions are experiencing inverse meteorological changes induced by TPE anomalies.

\section{CONCLUSIONS}

Several studies have noted the linkage between climate patterns and winter haze pollution in China (Feng et al., 2010; Hui and Xiang, 2015; Feng et al., 2016; Zhao et al., 2016; Zou et al., 2017; Hung et al., 2018; Lin et al., 2018), yet the influence of TP forcing on haze pollution in the hazeprone area of eastern China has received much less attention. In this study, we discussed the association of TP climate modulation on favourable weather conditions for winter haze pollution over eastern China using a new metric - total atmospheric energy. The mechanism analysis results were further confirmed by WRF-Chem simulation experiments.

TPE has exhibited an increasing trend over recent decades, and its correlation with de-trended haze occurrences displayed significant differences in northern and southern China. WRF-Chem model were used to confirm the results of correlation analysis between TPE and haze occurrences by simulating two cases in December with high TPE $(97.98 \times$ $\left.10^{6} \mathrm{~J} \mathrm{~m}^{-2}\right)$ in 2016 and low TPE $\left(95.85 \times 10^{6} \mathrm{~J} \mathrm{~m}^{-2}\right)$ in 2013. With the $2.13 \times 10^{6} \mathrm{~J} \mathrm{~m}^{-2}$ increase in TPE, the responses of $\mathrm{PM}_{2.5}$ concentrations can reach around $20 \mu \mathrm{g} \mathrm{m}^{-3}$, exhibiting positive $\mathrm{PM}_{2.5}$ anomalies in northern China and negative $\mathrm{PM}_{2.5}$ anomalies in southern China. The higher pollutant emissions in northern China may amplify the climate modulation

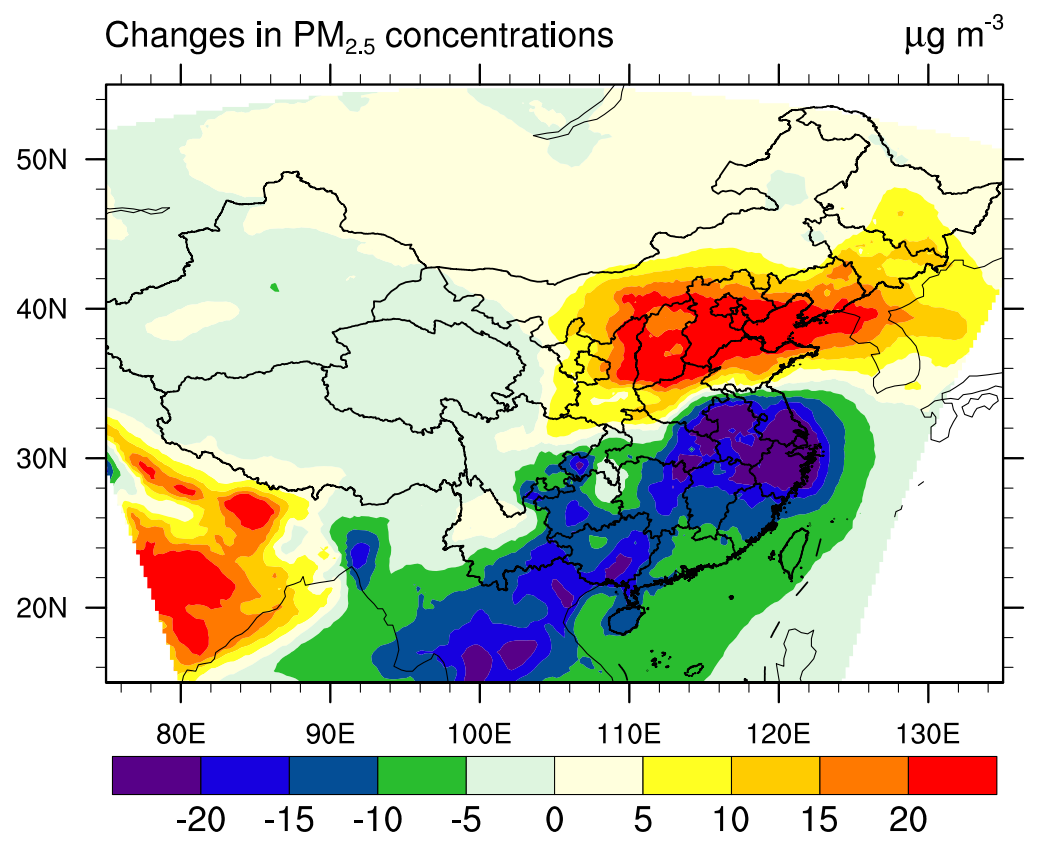

Fig. 7. Changes in monthly averaged $\mathrm{PM}_{2.5}$ concentrations $\left(\mu \mathrm{g} \mathrm{m}^{-3}\right)$ in response to high TPE. 

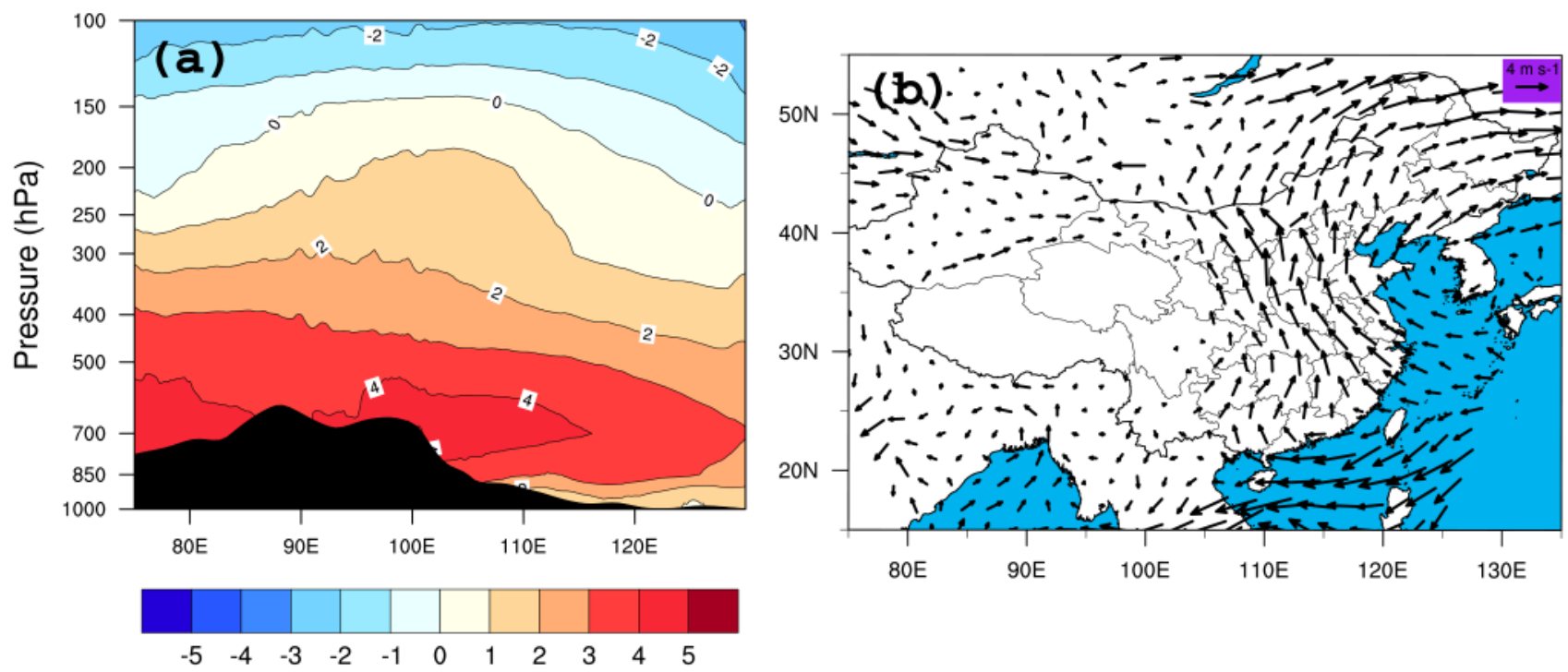

Fig. 8. Responses of monthly averaged (a) vertical air temperature $\left({ }^{\circ} \mathrm{C}\right.$ ) averaged along $27-41^{\circ} \mathrm{N}$ and (b) $\mathrm{U}$ and $\mathrm{V}$ windvector components at $850 \mathrm{hPa}$ to high TPE.

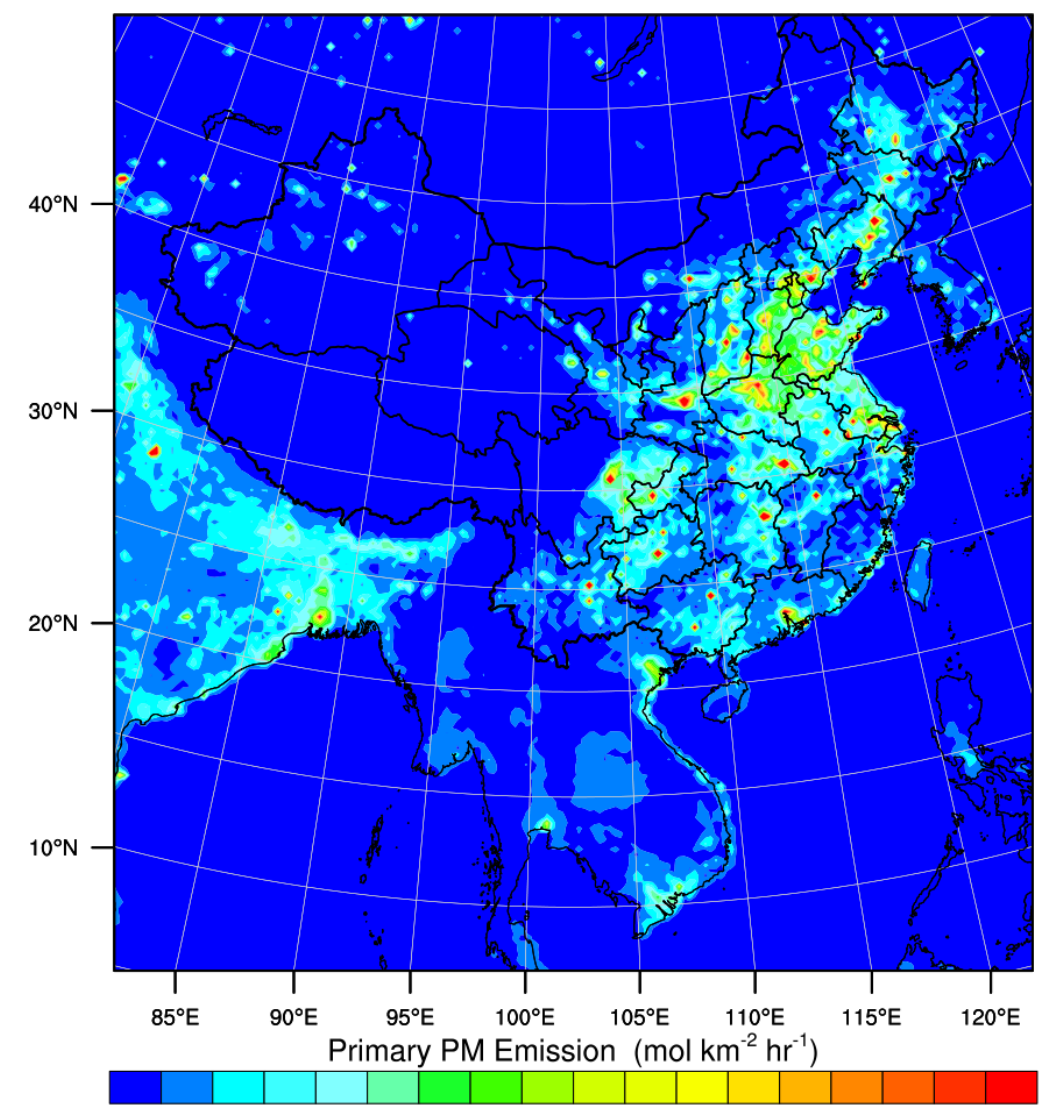

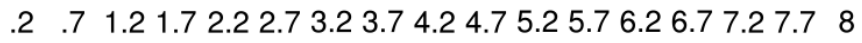

Fig. 9. Spatial distribution of primary particulate matter $\left(\mathrm{PM}_{2.5}\right)$ emissions reported for 2010 in MIX inventory for Asia as used in the model simulation.

impacts of the TP. TP climate modulation leads to more rapid warming in the low troposphere, a weakened East Asia winter monsoon, and enhanced wind speeds in southern China.

To separate the influence of pollutant emissions and meteorological conditions on haze events, we removed liner trends in the occurrence of haze days, which might not exactly represent the haze pollution only under meteorological impact. In both WRF-Chem model simulation experiments, 
we adopted the same levels of anthropogenic aerosol emissions, thus totally removing the effects of pollutant emissions. These emissions may have impacted our results. However, our results nevertheless suggest circulation changes induced by TPE anomalies can play important roles in air pollution over eastern China and must be accounted for in discussions of climate-modulation drivers of air pollution. Under the context of climate warming, the effect of TPE on winter haze pollution could be more significant through affecting the atmosphere circulation in eastern China. In the future, long-term prediction of haze frequency using the association of the climate-related TPE with haze in eastern China, quantifying the TP responses to climate warming and then modulation on air pollution in eastern China need to be investigated. Overall, the findings in this study could help construct a more accurate statistical model to predict wintertime haze pollution over eastern China using a combination of climate indices, and emission control plans could be implemented accordingly to minimize damage from potential deterioration in subsequent air quality.

\section{ACKNOWLEDGEMENTS}

This study was jointly funded by National Key R \& D Pilot Research Projects of China (2016YFC0203304), National Natural Science Foundation of China (41830965, 91644223 and 91744209), and Chinese Third Tibetan Plateau Atmospheric Experiment (GYHY201406001).

\section{REFERENCES}

An, Z., Huang, R.J., Zhang, R., Tie, X., Li, G., Cao, J., Zhou, W. and Ji, Y. (2019). Severe haze in northern China: A synergy of anthropogenic emissions and atmospheric processes. Proc. Natl. Acad. Sci. U.S.A. 116: 8657-8666.

Cai, W., Li, K., Liao, H., Wang, H. and Wu, L. (2017). Weather conditions conducive to Beijing severe haze more frequent under climate change. Nature Clim. Change 7: 257-262.

Chen, H. and Wang, H. (2015). Haze days in North China and the associated atmospheric circulations based on daily visibility data from 1960 to 2012 . J. Geophys. Res. 120: 5895-5909.

Cheng, X., Zhao, T., Gong, S., Xu, X., Han, Y., Yin, Y., Tang, L., He, H. and He, J. (2016). Implications of East Asian summer and winter monsoons for interannual aerosol variations over central-eastern China. Atmos. Environ. 129: 218-228.

Ding, Y. (1994). Monsoons over China, Springer, Dordrecht.

Ding, Y. and Liu, Y. (2014). Analysis of long-term variations of fog and haze in China in recent 50 years and their relations with atmospheric humidity. Sci. China Earth Sci. 57: 36-46.

Duan, A., Guoxiong, W.U., Zhang, Q. and Liu, Y. (2006). New proofs of the recent climate warming over the Tibetan Plateau as a result of the increasing greenhouse gases emissions. Chinese Sci. Bull. 51: 1396-1400.

Fang, X., Luo, S. and Lyu, S. (2019). Observed soil temperature trends associated with climate change in the Tibetan Plateau, 1960-2014. Theor. Appl. Climatol. 135: 169-181.

Feng, J., Li, J., Zhu, J. and Hong, L. (2016). Influences of El Niño Modoki event 1994/95 on aerosol concentrations over southern China. J. Geophys. Res. 121: 1637-1651.

Feng, N., Li, Z., Li, C., Lee, K.H. and Wang, M. (2010). Increase of wintertime fog in China: Potential impacts of weakening of the Eastern Asian monsoon circulation and increasing aerosol loading. J. Geophys. Res. 115: D00K20.

Fu, G.Q., Xu, W.Y., Yang, R.F., Li, J.B. and Zhao, C.S. (2014). The distribution and trends of fog and haze in the North China Plain over the past 30 years. Atmos. Chem. Phys. 14: 11949-11958.

Fu, H. and Chen, J. (2017). Formation, features and controlling strategies of severe haze-fog pollutions in China. Sci. Total Environ. 578: 121-138.

Gao, M., Sherman, P., Song, S., Yu, Y., Wu, Z. and McElroy, M.B. (2019). Seasonal prediction of Indian wintertime aerosol pollution using the ocean memory effect. Science Advances 5: eaav4157.

Gong, S.L., Zhao, T.L., Sharma, S., Toom-Sauntry, D., Lavoué, D., Zhang, X.B., Leaitch, W.R. and Barrie, L.A. (2010). Identification of trends and interannual variability of sulfate and black carbon in the Canadian High Arctic: 1981-2007. J. Geophys. Res. 115: D07305.

Guo, S., Hu, M., Zamora, M.L., Peng, J. and Zhang, R. (2014). Elucidating severe urban haze formation in China. Proc. Natl. Acad. Sci. U.S.A. 111: 17373.

Huang, R.J., Zhang, Y., Bozzetti, C., Ho, K.F., Cao, J.J., Han, Y., Daellenbach, K.R., Slowik, J.G., Platt, S.M., Canonaco, F., Zotter, P., Wolf, R., Pieber, S.M., Bruns, E.A., Crippa, M., Ciarelli, G., Piazzalunga, A., Schwikowski, M., Abbaszade, G., Schnelle-Kreis, J., Zimmermann, R., An, Z., Szidat, S., Baltensperger, U., Haddad, I.E. and Prévôt, A.S.H. (2014). High secondary aerosol contribution to particulate pollution during haze events in China. Nature 514: 218-222.

Huang, X., Wang, Z. and Ding, A. (2018). Impact of aerosol-PBL interaction on haze pollution: Multi-year observational evidences in North China. Geophys. Res. Lett. 45: 8596-8603.

Hui, G. and Xiang, L. (2015). Influences of El Nino Southern Oscillation events on haze frequency in eastern China during boreal winters. Int. J. Climatol. 35: 26822688.

Hung, C.H., Lo, K.C. and Yuan, C.S. (2018). Forming highly polluted PMs caused by the invasion of transboundary air pollutants: Model simulation and discussion. Aerosol Air Qual. Res. 18: 1698-1719.

Ji, Z. (2018). Advances and prospects of research on simulating transboundary black carbon and their climatic effects over the Tibetan Plateau. Prog. Geogr. 37: 465475.

Jiang, Q., Wang, F. and Sun, Y. (2019). Analysis of chemical composition, source and processing characteristics of submicron aerosol during the summer in Beijing, China. Aerosol Air Qual. Res. 19: 1450-1462.

Li, M., Zhang, Q., Kurokawa, J.I, Woo, J.H., He, K., Lu, Z., 
Ohara, T., Song, Y., Streets, D.G. and Carmichael, G.R. (2017). MIX: A mosaic Asian anthropogenic emission inventory under the international collaboration framework of the MICS-Asia and HTAP. Atmos. Chem. Phys. 17: 34813-34869.

Li, Q., Zhang, R. and Wang, Y. (2015). Interannual variation of the wintertime fog-haze days across central and eastern China and its relation with East Asian winter monsoon. Int. J. Climatol. 36: 346-354.

Lin, P., Yan, Z., Sun, Z., Miao, S. and Yao, Y. (2018). Increasing persistent haze in Beijing: potential impacts of weakening East Asian winter monsoons associated with northwestern Pacific sea surface temperature trends. Atmos. Chem. Phys. 18: 3173-3183.

Liu, X.D. and Chen, B.D. (2000). Climatic warming in the Tibetan plateau during recent decades. Int. J. Climatol. 20: 1729-1742.

Liu, X., Meng, J., Hou, Z., Yan, L., Wang, G., Yi, Y., Wei, B., Fu, M., Li, J. and Cao, J. (2019). Molecular Compositions and sources of organic aerosols from urban atmosphere in the north China plain during the wintertime of 2017. Aerosol Air Qual. Res. 19: 2267-2280.

Ma, Q., Wu, Y., Tao, J., Xia, Y., Liu, X., Zhang, D., Han, Z., Zhang, X. and Zhang, R. (2017a). Variations of chemical composition and source apportionment of $\mathrm{PM}_{2.5}$ during winter haze episodes in Beijing. Aerosol Air Qual. Res. 17: 2791-2803.

Ma, Y., Ma, W., Zhong, L., Hu, Z., Li, M., Zhu, Z., Han, C., Wang, B. and Liu, X. (2017b). Monitoring and modelling the Tibetan Plateau's climate system and its impact on East Asia. Sci. Rep. 7: 44574.

Renhe, Z., Li, Q. and Zhang, R.N. (2014). Meteorological conditions for the persistent severe fog and haze event over eastern China in January 2013. Sci. China Earth Sci. 57: $26-35$.

Shang, X., Lee, M., Han, J., Kang, E., Kim, S.W., Gustafsson, Ö. and Chang, L. (2018). Identification and chemical characteristics of distinctive Chinese outflow plumes associated with enhanced submicron aerosols at the Gosan climate observatory. Aerosol Air Qual. Res. 18: 330-342.

Sheng, P.X., Mao, J.T., Li, J.G., Zhang, A.C., Sang, J.G. and Pan, N.X. (2013). Atmospheric Physics, Peking University Press, Beijing.

Sun, Z., Duan, F., Ma, Y., He, K., Zhu, L. and Ma, T. (2019). Heavy particulate matter pollution during the 2014-2015 winter in Tianjin, China. Aerosol Air Qual. Res. 19: 13381345.
Wu, G., Liu, Y., Zhang, Q., Duan, A., Wang, T., Wan, R., Liu, X, Li, W., Wang, Z. and Liang, X. (2007). The influence of mechanical and thermal forcing by the Tibetan Plateau on Asian climate. J. Hydrometeorol. 8: 770-789.

Xu, X., Zhao, T., Liu, F., Gong, S.L., Kristovich, D., Lu, C., Guo, Y., Cheng, X., Wang, Y. and Ding, G. (2016). Climate modulation of the Tibetan Plateau on haze in China. Atmos. Chem. Phys. 16: 1365-1375.

Yanai, M. and Wu, G.X. (2006). Effects of the Tibetan Plateau. Asian Monsoon 29: 513-549.

Yang, M., Nelson, F.E., Shiklomanov, N.I., Guo, D. and Wan, G. (2010) Permafrost degradation and its environmental effects on the Tibetan Plateau: A review of recent research. Earth Sci. Rev. 103: 31-44.

Ye, D.Z. and Gao, Y.X. (1979). Meteorology of the QinghaiXizang Plateau, Chinese Science Press, Beijing, China. (in Chinese)

Yi, K., Liu, J., Wang, X., Ma, J., Hu, J., Wan, Y., Xu, J., Yang, H., Liu, H., Xiang, S. and Tao, S. (2019). A combined Arctic-tropical climate pattern controlling the inter-annual climate variability of wintertime $\mathrm{PM}_{2.5}$ over the North China Plain. Environ. Pollut. 245: 607-615.

Yin, Z. and Wang, H. (2016). The relationship between the subtropical Western Pacific SST and haze over NorthCentral North China Plain. Int. J. Climatol. 36: 34793491.

Yu, J., Yan, C., Liu, Y., Li, X., Zhou, T. and Zheng, M. (2018). Potassium: A tracer for biomass burning in Beijing? Aerosol Air Qual. Res. 18: 2447-2459.

Zhao, S., Li, J. and Sun, C. (2016). Decadal variability in the occurrence of wintertime haze in central eastern China tied to the Pacific Decadal Oscillation. Sci. Rep. 6: 27424.

Zhong, J., Zhang, X., Dong, Y., Wang, Y., Liu, C., Wang, J., Zhang, Y. and Che, H. (2017). Feedback effects of boundary-layer meteorological factors on cumulative explosive growth of $\mathrm{PM}_{2.5}$ during winter heavy pollution episodes in Beijing from 2013 to 2016. Atmos. Chem. Phys. 18: 247-258.

Zou, Y., Wang, Y., Zhang, Y. and Koo, J.H. (2017). Arctic sea ice, Eurasia snow, and extreme winter haze in China. Sci. Adv. 3: e1602751.

Received for review, February 8, 2020 Revised, March 10, 2020 Accepted, March 11, 2020 